\title{
Daily step counts were associated with suicide in all 47 prefectures of Japan ${ }^{*}$
}

\author{
Nobuyuki Miyatake ${ }^{1}$, Noriko Sakano ${ }^{1}$, Akira Yoshioka², Takeshi Yoda ${ }^{2}$, Takeshi Suzue ${ }^{2}$, \\ Tomohiro Hirao ${ }^{2}$
}

${ }^{1}$ Department of Hygiene, Faculty of Medicine, Kagawa University, Miki, Kagawa, Japan

${ }^{2}$ Department of Public Health, Faculty of Medicine, Kagawa University, Miki, Kagawa, Japan

Email: miyarin@med.kagawa-u.ac.jp

Received 21 February 2013; revised 22 March 2013; accepted 1 April 2013

Copyright (C) 2013 Nobuyuki Miyatake et al. This is an open access article distributed under the Creative Commons Attribution License, which permits unrestricted use, distribution, and reproduction in any medium, provided the original work is properly cited.

\begin{abstract}
The link between suicide and daily step counts was evaluated in all 47 prefectures of Japan by ecological study. The crude rate of suicide was significantly and negatively correlated with daily step counts. However, the association between the age-adjusted rate of suicide and daily step counts was noted only in men. These results suggest that increasing daily step counts may be useful for preventing suicide, especially in men, in Japan.
\end{abstract}

Keywords: Suicide; Daily Step Counts; Ecological Study; Japan

\section{INTRODUCTION}

Death due to suicide has become public health challenge in Japan as well as in the world [1]. For example, about thirty thousand people due to suicide have been reported in Japan for these ten years. There are many reports according to the cause of suicide i.e. health and socioeconomic factors [2]. Disability, which may induce less physical activity, is an important independent correlate of suicidal ideation [3]. However, the link between suicide and physical activity expressed as daily step counts has not been fully discussed. Therefore, we investigated the relationship between suicide and daily step counts in all 47 prefectures of Japan by ecological study.

\section{METHODS}

The crude and age-adjusted rate of suicide (per a hundred thousand people) in all 47 prefectures of Japan in 2010 was obtained from official web site in Cabinet Office, Government of Japan [1] and Ministry of Internal Affairs

\footnotetext{
"There is no conflict of interest.
}

of Communications, Japan [4]. Daily step counts of each subject (single day) were measured in National Nutrition Survey, Japan. Mean of daily step counts, which were adjusted for age, from 2006 to 2010 in all 47 prefectures of Japan was also obtained from official web site in Ministry from Labour and Welfare, Japan [5].

A simple correlation analysis was used to test the significance of the linear relationship among continuous variables: $p<0.05$ was considered to be statistically significant.

\section{RESULTS}

In all 47 prefectures of Japan, the crude rate of suicide (per a hundred thousand people) was $26.4 \pm 4.0$ and ageadjusted rate of suicide (per a hundred thousand people) was $31.3 \pm 4.0$ in men and $11.3 \pm 1.4$ in women. Daily step counts were $6997.9 \pm 543.5$ in men and $6103.3 \pm$ 427.1 in women. By simple correlation analysis, the crude rate of suicide was significantly and negatively correlated with daily step counts (Figure 1). According to simple regression line, an increase in a thousand daily step counts corresponded to a reduction of 4 men and 6 womens' death due to suicide (per a hundred thousand people) in Japan. In addition, age-adjusted rate of suicide was significantly and negatively correlated with daily step counts in men $(\mathrm{r}=-0.563, p<0.0001)$. However, the association between age-adjusted rate of suicide and daily step counts was attenuated in women $(\mathrm{r}=-0.198, p$ $=0.1815)$, not at a significant level.

\section{DISCUSSION}

We firstly explored the link between suicide and physical activity expressed as daily step counts in Japan.

It is well known that increasing daily step counts prevent and improve lifestyle-related disease [6]. Tsunoda, $\mathrm{K}$. 

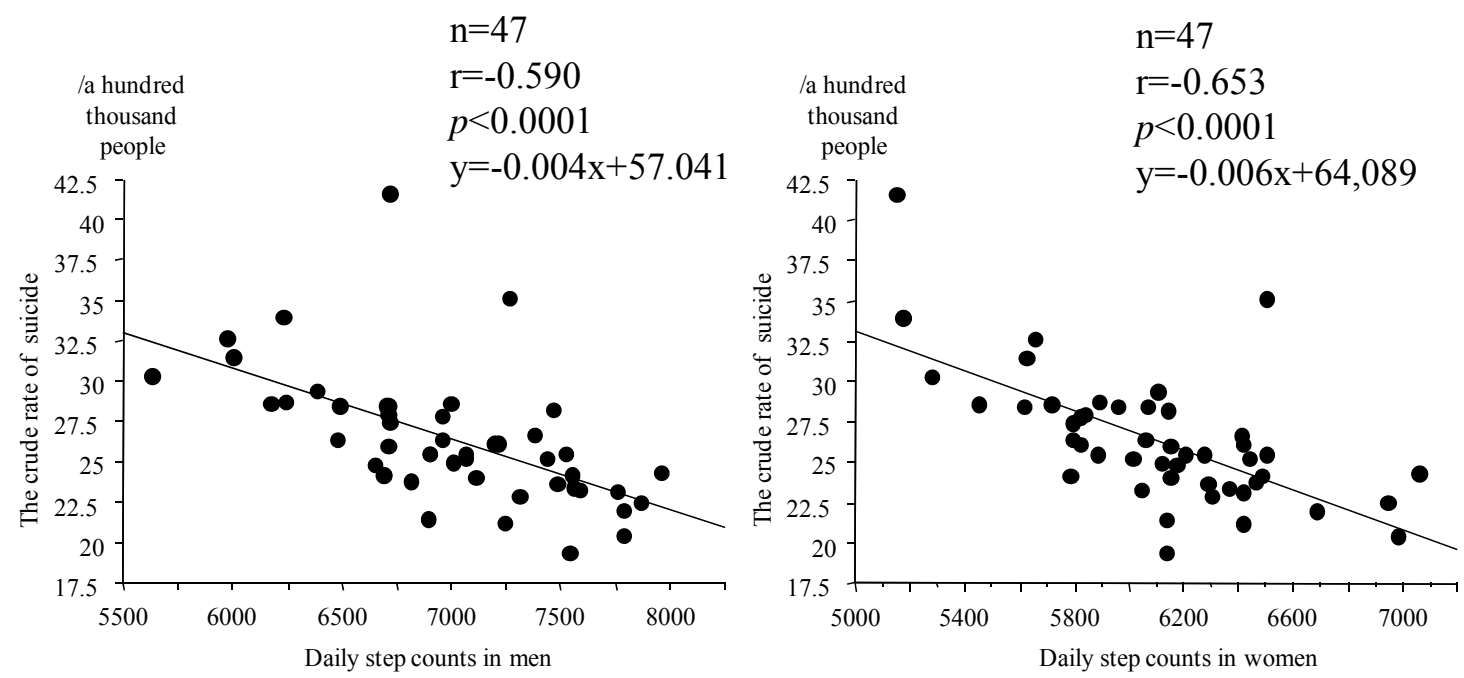

Figure 1. Simple correlation analysis between the crude rate of suicide and daily step counts in all 47 prefectures of Japan.

et al. reported that total physical activity was significantly correlated with Geriatric Depression Scale in 2100 community-dwelling Japanese adults [7]. Depressive symptoms were significantly associated with physical activity less than once a week and daily hours of sleep of 6 hours or less in Japanese male workers [8]. In addition, disability is an important independent correlate of suicidal ideation, particularly in older people by 8550 randomly selected adults in Great Britain [3]. Taken together, in primal clinical care, an increase in physical activity is may be considered and be useful for preventative program of suicide, especially in men.

Potential limitations still remain in this study. First, we used an ecological study. The link between suicide and daily step counts may not apply for the link among individuals. Second, other many confounding factors i.e. socio-economic status, population size, population density, proportion of people aged 65 or over, proportion of workers in the 1st industry and proportion of people with disability were not evaluated in this study. The third, only daily step counts of physical activity was used for analysis. These limitations may induce inaccurate results, and we could not evaluate the link between suicide and daily step counts as accurately as we wished. Further ongoing investigations are urgently required to prove such a link.

\section{REFERENCES}

[1] Cabinet Office, Government of Japan (2011) Suicide in Japan. (in Japanese) http://www.npa.go.jp/safetylife/seianki/H22jisatsunogaiy ou.pdf
[2] Howton, K. and van Heeringen, K. (2009) Suicide. Lancet, 373, 1372-1381.

[3] Dennis, S., Baillon, S., Brugha, T., Lindesay, J., Stewart, R. and Meltzer, H. (2009) The influence of limitation in activity of daily living and physical health on suicidal ideation: results from a population survey of Great Britain. Social Phyciatry and Phyciatric Epidemiolgy, 44, 608613.

[4] Ministry of Internal Affairs and Communications, Japan (2010) Age adjusted mortality rate of suicide in all 47 prefectures of Japan. (in Japanese)

http://www.e-stat.go.jp/SG1/estat/GL08020103.do? toG $\underline{\mathrm{L} 08020103 \text { \&listID }=000001101037 \& \text { requestSender }=\text { sea }}$ rch

[5] Ministry of Labour and Welfare, Japan (2010) The national nutrition survey. (in Japanese)

http://www.mhlw.go.jp/bunya/kenkou/eiyou/dl/h22-houk oku-11.pdf

[6] Miyatake, N., Nishikawa, H., Morishita, A., Kunitomi, M., Wada, J., Suzuki. H., Takahashi, K., Makion, H., Kira, S. and Fujii, M. (2002) Daily walking reduces visceral adipose tissue areas and improves insulin resistance in Japanese obese subjects. Diabetes Research and Clinical Practice, 58, 101-107.

[7] Tsunoda, K., Mitsuishi, Y., Tsuji, T., Yoon, J.Y., Muraki, T., Hotta, K. and Okura, T. (2011) Association of the physical activity of community-dwelling older adults with transportation modes, depression and social networks. Nishon Ronen Igakkai Zasshi, 48, 516-523. (in Japanese)

[8] Wada, K., Satoh, T., Tsunoda, M., Aizawa, Y. and Japan Work Stress and Health Cohort Study Group (2006) Associations of health behaviors on depressive symptoms among employed men in Japan. Industrial Health, 44, 486-492. 